LA-UR- $98-4233$

Title:

STABILITY OF TRILATERAL FORCES:

III. LARGE UNSYMMETRIC FORCES

Author(s):

Gregory H. Canavan, P-DO

RECEIVEC

AllG 18.1999

OSTI

Submitted to:

For discussions outside the Laboratory

Date: 18 September 1998

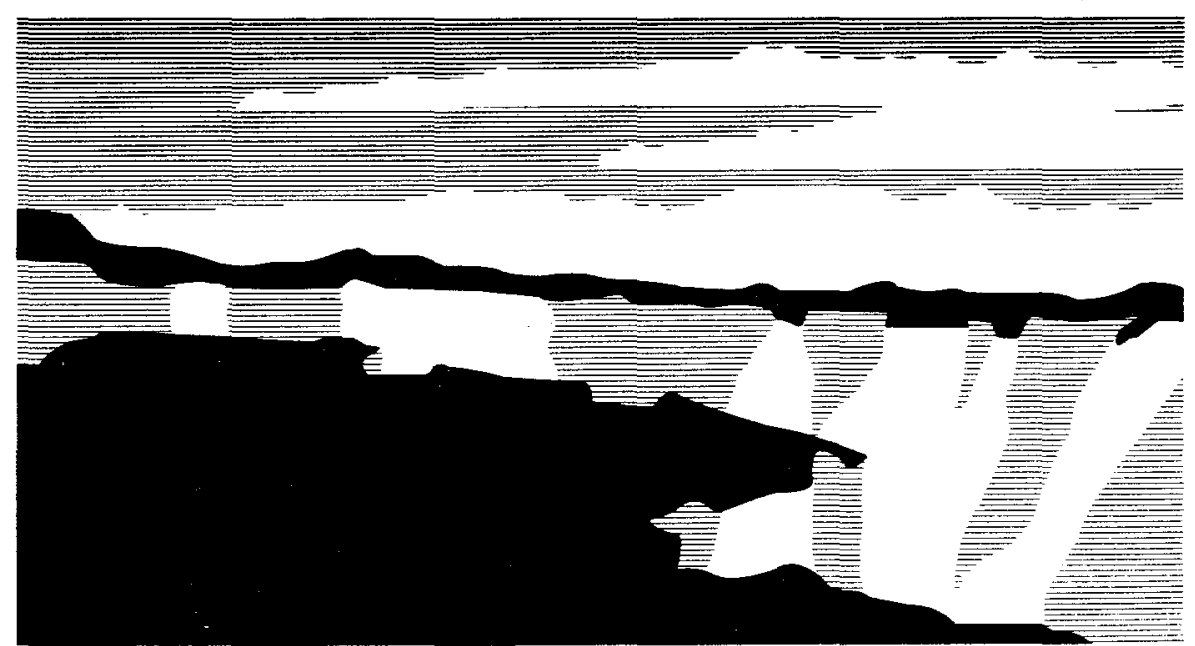

Los Alamos National Laboratory, an affirmative action/equal opportunity employer, is operated by the University of California for the U.S. Department of Energy under contract W-7405-ENG-36. By acceptance of this . 7 ticle, the publisher recognizes that the U.S. Government retains a nonexclusive, royalty-free license to publish or reproduce the published form of this contribution, or to allow others to do so, for U.S. Government purposes. The Los Alamos National Laboratory requests that the publisher identify this article as work performed under the auspices of the U.S. Department of Energy. 


\section{DISCLAIMER}

This report was prepared as an account of work sponsored by an agency of the United States Government. Neither the United States Government nor any agency thereof, nor any of their employees, make any warranty, express or implied, or assumes any legal liability or responsibility for the accuracy, completeness, or usefulness of any information, apparatus, product, or process disclosed, or represents that its use would not infringe privately owned rights. Reference herein to any specific commercial product, process, or service by trade name, trademark, manufacturer, or otherwise does not necessarily constitute or imply its endorsement, recommendation, or favoring by the United States Government or any agency thereof. The views and opinions of authors expressed herein do not necessarily state or reflect those of the United States Government or any agency thereof. 


\section{DISCLAIMER}

Portions of this document may be illegible in electronic image products. Images are produced from the best available original document. 


\title{
STABILITY OF TRILATERAL FORCES: III. LARGE UNSYMMETRIC FORCES
}

\author{
Gregory H. Canavan
}

\begin{abstract}
For large unsymmetric forces, at few weapons per missile all forces are reserved, costs are constant, and configurations are stable. At many weapons per missile, no weapons are reserved, and stability degrades. For small unequal forces, the equal sides ignore the smaller forces and deter each other as in bilinear engagements. For large unequal forces, the equal sides ignore each other, commit all forces to the unequal side, and stability indices approach those observed for large triads.
\end{abstract}

Companion papers extend the theory for bilateral interactions to the stability of modest ${ }^{1}$ and large symmetric forces. ${ }^{2}$ This note extends that analysis to large unsymmetric trilateral forces in which two sides have equal forces and the third has forces of arbitrary size. For such forces, as for modest and symmetric forces earlier, the analysis predicts that for few weapons per missile, all forces are reserved, but for many weapons per missile, none are. The former leads to stability; the latter to decreasing costs, fractionation, and degrading stability. These results correspond to those found earlier for moderate and symmetric forces. For small unequal forces, the equal sides ignore the smaller forces and deter each other as in bilinear engagements. For large unequal forces, the equal sides ignore each other, commit all forces to the unequal side, and stability indices approach those observed for large triads.

Exchange between the two equal sides are treated by establishing a reserve for the unequal side and then using the optimization techniques derived earlier to minimize the first strike costs between the equal sides. ${ }^{3}$ Each has $\mathrm{M}$ vulnerable missiles with $\mathrm{m}$ weapons each and $\mathrm{N}$ survivable missiles with $\mathrm{n}$ weapons each for a total of $\mathrm{W}=\mathrm{mM}+\mathrm{nN}$ weapons. Each withholds a fraction $1-\mathrm{g}$ and commits $\mathrm{gW}$ weapons to the exchange between them. The side that strikes first delivers $\mathrm{f} \mathrm{gW}$ weapons on the other's $\mathrm{M}$ vulnerable missiles and the rest in a first strike on military value targets of magnitude

$$
\mathrm{F}=(1-\mathrm{f}) \mathrm{g}(\mathrm{mM}+\mathrm{nN})=(1-\mathrm{f}) \mathrm{gW},
$$

This counterforce strike delivers an average of $r=f W / M$ weapons on each vulnerable missile, which gives them a survival probability $Q \approx q^{r}$, where $p=1-q$ is the missile single shot probability of kill. The other's second strike on value is then

$$
\mathrm{S}=\mathrm{g}(\mathrm{QmM}+\mathrm{nN}) \text {. }
$$

where for simplicity it is assumed that the reserve fraction is the same for both first and second strike and vulnerable and survivable forces. First and second strikes are converted into costs through exponential approximations to the value of military value targets destroyed, assuming that each side has $1 / \mathrm{k} \sim 1,000$ value targets. The cost of damage to self and incomplete damage 
to other are joined with a weighting parameter $\mathrm{L}$ that measures the attacker's relative preference for damage to other and prevention of damage to self. ${ }^{4}$ The costs of striking first and second are

$$
\begin{aligned}
& \mathrm{C}_{1} \approx\left(1-\mathrm{e}^{-\mathrm{kS}}+\mathrm{L} \mathrm{e}^{-\mathrm{kF}}\right) /(1+\mathrm{L}), \\
& \mathrm{C}_{2} \approx\left(1-\mathrm{e}^{-\mathrm{kF}}+\mathrm{L} \mathrm{e}^{-\mathrm{kS}}\right) /(1+\mathrm{L}),
\end{aligned}
$$

and the conventional cost ratio stability index is

$$
\mathrm{I}=\mathrm{C}_{1} / \mathrm{C}_{2} \text {. }
$$

Exchanges between unequal sides are treated by an extension of this procedure. Either of the two sides above has up to $(1-\mathrm{g}) \mathrm{W}$ weapons for an exchange with the unequal side, so his first strike is

$$
F^{\prime \prime}=\left(1-f^{\prime \prime}\right) g \text { 'W, }
$$

where g" is the fraction allocation to the strike and $\mathrm{f}^{\prime}$ is the fraction of it allocated to vulnerable targets. Since the fractions $\mathrm{g}+\mathrm{g} " \leq 1$, he must balance his allocation between the equal and unequal sides and between force and value in each interaction. His second strike is

$$
S^{\prime \prime}=g \text { " }(Q " m M+n N) \text {. }
$$

The unequal side has $W^{\prime}=m^{\prime} M^{\prime}+n^{\prime} N^{\prime}$ weapons, of which he commits a fraction $g^{\prime}$ to the interaction with one side and up to $1-g^{\prime}$ to the other. However, those two interactions are symmetrical, so $g$ ' is the same for each and is only constrained by $2 g^{\prime} \leq 1$. Thus, his first and second strikes are

$$
\begin{aligned}
& F^{\prime}=\left(1-f^{\prime}\right) g^{\prime} W^{\prime}, \\
& S^{\prime}=g^{\prime}\left(Q^{\prime} m^{\prime} M^{\prime}+n^{\prime} N^{\prime}\right) .
\end{aligned}
$$

Results. While these equations are nonlinear, they can be solved by iteration for the $\mathrm{g}$ and fs that minimize the $\mathrm{C}_{1} \mathrm{~s}$ for any set of forces $\mathrm{m}$. Figure 1 shows the reserves for each side a function of the number of weapons on each missile $\mathrm{m}^{\prime}$ of the uneven side for $\mathrm{m}=2, \mathrm{M}=\mathrm{M}^{\prime}=$ 250 , and $\mathrm{nN}=0$ for ease of comparison with the results of the previous papers. For small m', i.e., smaller unequal forces, $\mathrm{g}=1, \mathrm{~g}^{\prime}=0.5$, and $\mathrm{g}^{\prime \prime}=0$, indicating a large commitment of forces for engagements between the larger equal sides and by the smaller unequal side to engagements with the larger forces, but no commitment of forces by the equal sides to the engagement with the smaller unequal force. That is, the smaller forces is ignored.

As $\mathrm{m}^{\prime}$ passes 1.5, the unequal force approaches each equal force, and the unequal force becomes dominant. Thus, $g$ drops to zero as the equal sides begin to ignore one another and $g$ " approaches unity, as they shift weapons to the interaction with the unequal side. At the same time, the unequal side's commitment g' drops to zero as it no longer finds it necessary to commit forces to this engagement, which is analogous to the large $\mathrm{m}$ ' behavior of bilateral interactions.

Figure 2 shows the allocations between weapons and value, $f, f^{\prime}$, and f'. The allocation between equal missile forces is $\mathrm{f} \approx 0.6$ for small $\mathrm{m}^{\prime}$, decreasing slowly for larger $\mathrm{m}$ '. $\mathrm{f}$ ' shifts abruptly from unity to zero at $\mathrm{m}^{\prime} \approx 1.75$, where $\mathrm{f}^{\prime}$ shifts from zero to unity. 
Figure 3 shows the resulting first strikes. Those between the equal forces are $\approx 200$ until $m^{\prime}=1.5$, after which they drop to zero as those sides ignore each other. The unequal side first strike increases in proportion until $\mathrm{m}^{\prime}=1.5$, after which it falls to zero as it is no longer necessary for the unequal side to allocate missiles to the engagement with the equal sides. The second strike $F$ " by the equal sides to the unequal side is zero below 1.5 , and jumps by 1.75 to 500 , i.e., all of the weapons an equal side could generate.

Figure 4 shows the second strike. That between equal sides is $\approx 70$ for m' small and falls to zero for $m$ ' large, when no forces are committed between equals. The unequal side's $S$ ' increases for $\mathrm{m}^{\prime}$ small, and falls to zero at $\mathrm{m}^{\prime}=1.75$. The equal second strike on unequal jumps to 30 at $\mathrm{m}^{\prime}=1.75$ and then decays as the unequal force grows

Figure 5. shows the first strike cost. That for the equal forces is constant apart from the small jump between $m^{\prime}=1.5$ and 1.75 . The jump for the unequal force is somewhat larger. Three is also a large, discontinuous drop in the cost of equal side first strikes on unequal.

Figure 6 shows the second strike costs, which between equals and for unequal on equal are constant for small $\mathrm{m}$, and have a large jump at $\mathrm{m}=1.5$ to 0.6 . The cost for equal on unequal grow for small $\mathrm{m}^{\prime}$, drop at $\mathrm{m}^{\prime}=1.5$, and then remain constant at $\approx 0.3$.

Figure 7 shows the resulting stability indices. That between equals is unity for small $\mathrm{m}$ ' but falls to $\approx$ for $\mathrm{m}^{\prime}>1.75$. The index for unequal on an equal is significantly smaller for small $\mathrm{m}^{\prime}$, but similar for large $\mathrm{m}$ '. That for an equal on the unequal side is smaller still for small $\mathrm{m}$ ', but falls much less and is larger for large $\mathrm{m}$ '.

A conventional overall stability is defined as the minimum index over all sides at each $\mathrm{m}^{\prime}$. For $\mathrm{m}$ ' small, it is determined by that for an equal side on the unequal side For $\mathrm{m}^{\prime}=0$, it is 0.8 ; for small $\mathrm{m}$ ' it decreases linearly to $\approx 0.7$ at $\mathrm{m}^{\prime}=1.5$, after which the index between equal sides I drops below it to a constant value of $\approx 0.55$. The index for unequal on an equal side is always intermediate, although by $\mathrm{m}^{\prime}=3$ it approaches $\mathrm{I}$, which means that the dominant contribution to stability is evaluated to be the same by all three sides, which is appropriate, as all forces are comparable there.

Summary and conclusions. The first strike stability of unsymmetric trilateral configurations is discussed with an extension of the theory developed for bilateral configurations and tested on moderate and symmetric trilinear configurations. The approach assumes a reserve for other interactions, optimizes the first strike cost for the interaction at hand given that reserve, and varies the reserve to find the overall minimum. The results recover analogs to the earlier findings for moderate and symmetric forces that at few weapons per missile, all forces are reserved, which produces stability, and that at many weapons, none are reserved, which degrades stability. For small unequal forces, the equal sides ignore the smaller forces and deter each other 
as in bilinear engagements. For large unequal forces, the equal sides ignore each other, commit all forces to the unequal side, and stability indices approach those observed for large triads.

\section{References}

1. G. Canavan, "Stability of Trilinear Forces: I. Moderate Symmetric Forces," Los Alamos Report LA-UR-98-, September 1988.

2. G. Canavan, "Stability of Trilinear Forces: II. Large Symmetric Forces," Los Alamos Report LA-UR-98-, September 1998.

3. G. Canavan, "Considerations in Missile Reductions and Dealerting," L. Kruger ed, Proceedings of the World Federation of Scientists Working Group on Missile Proliferation and Defense (World Federation of Scientists, Lausanne, 1998); Los Alamos National Laboratory Report LA-UR-98-1426, April 1988.

${ }^{4}$. G. Kent and R. DeValk, "Strategic Defenses and the Transition to Assured Survival," RAND Report R-3369-AF, October, 1986. 
Fig. 1. Weapon commitments vs $\mathbf{m}^{\prime}$

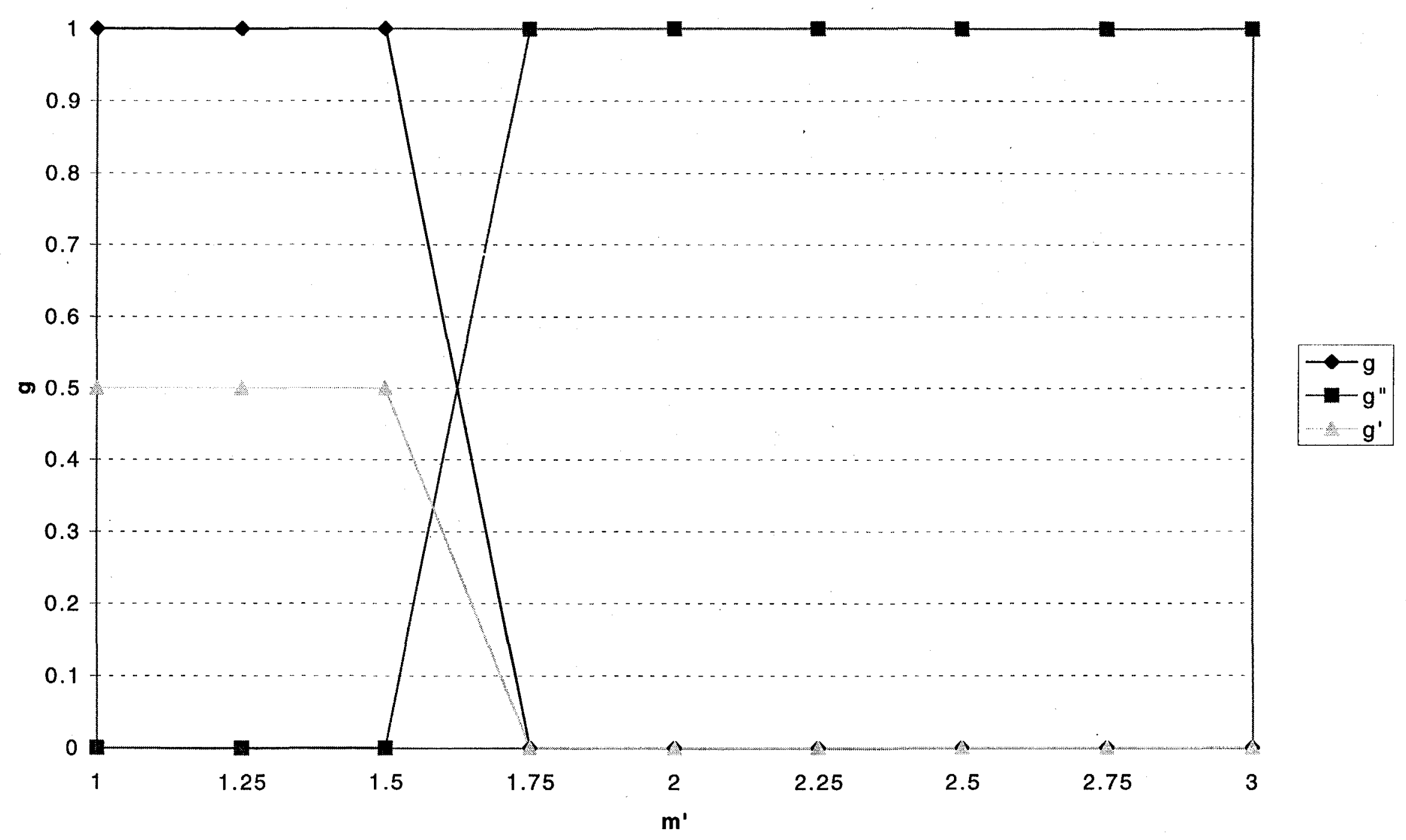

Page 1 


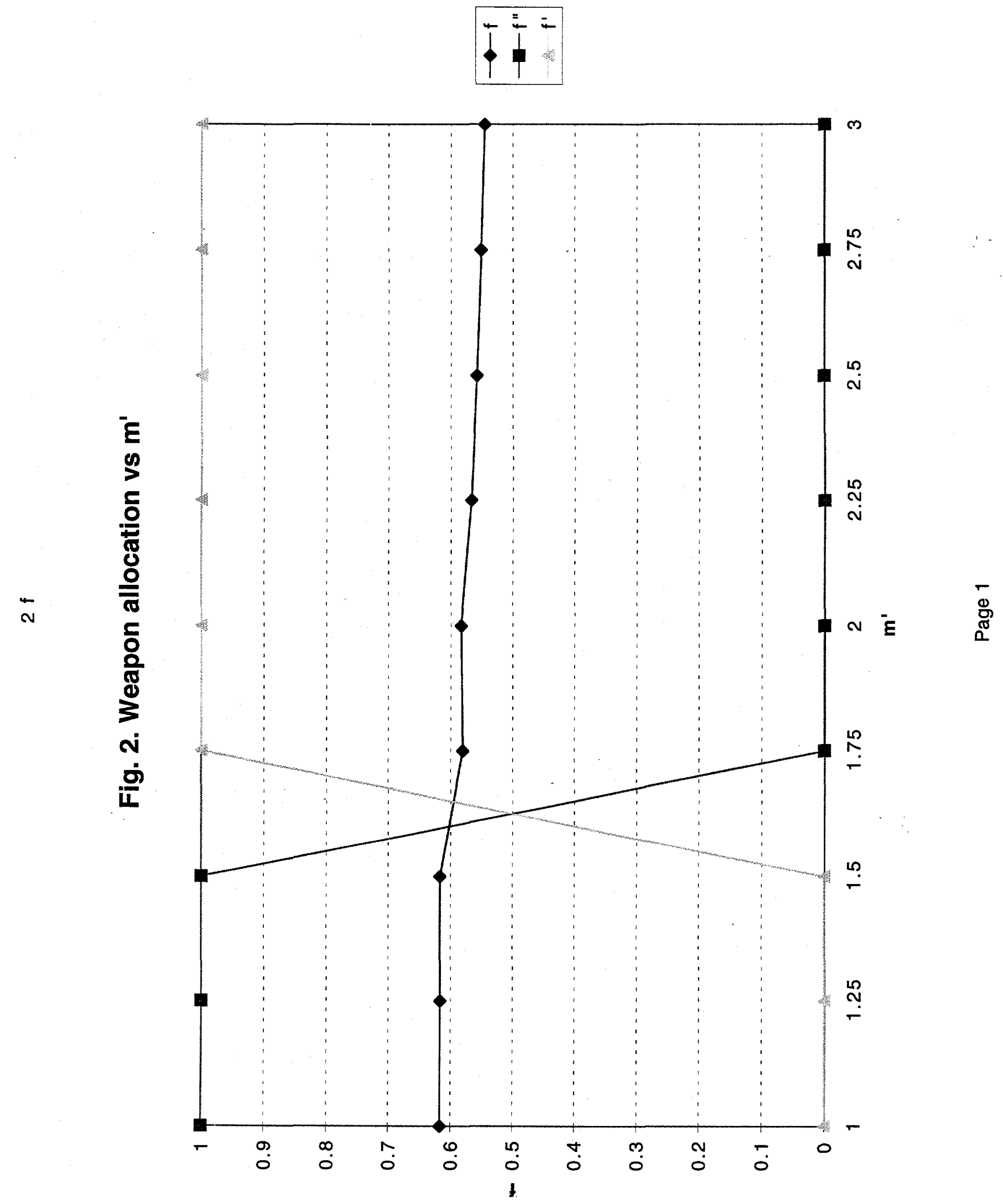



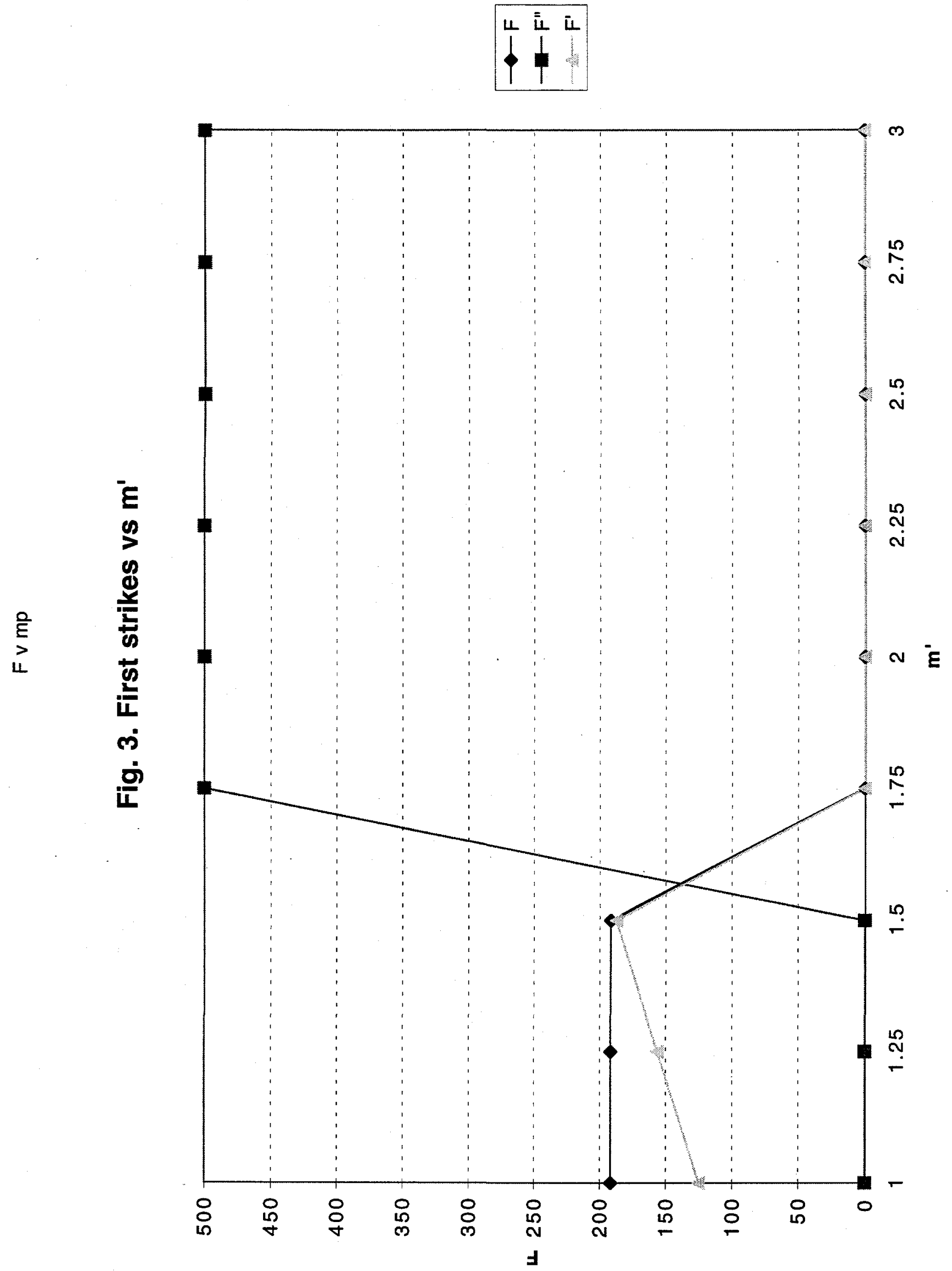

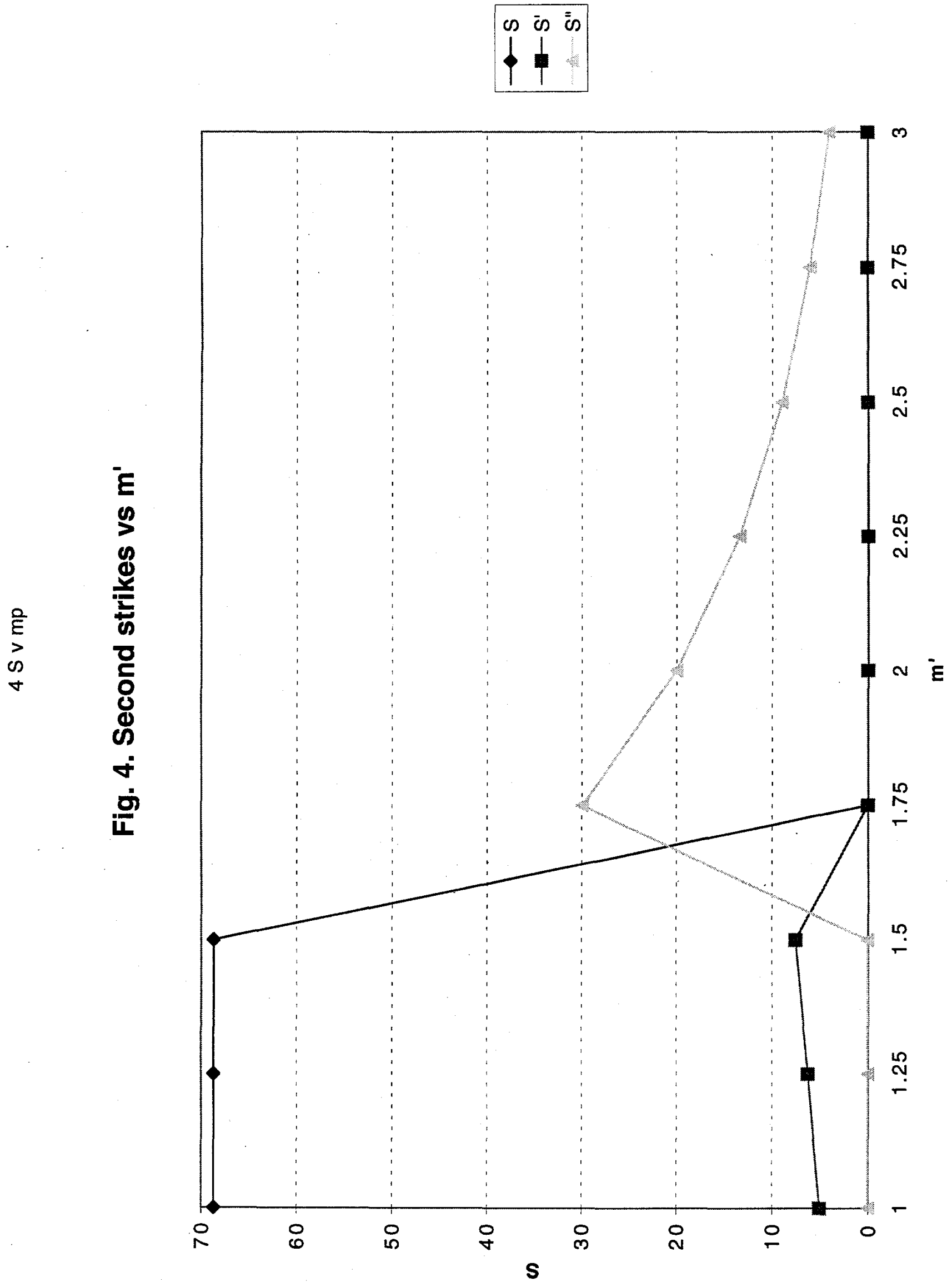

ฐ্ণ 


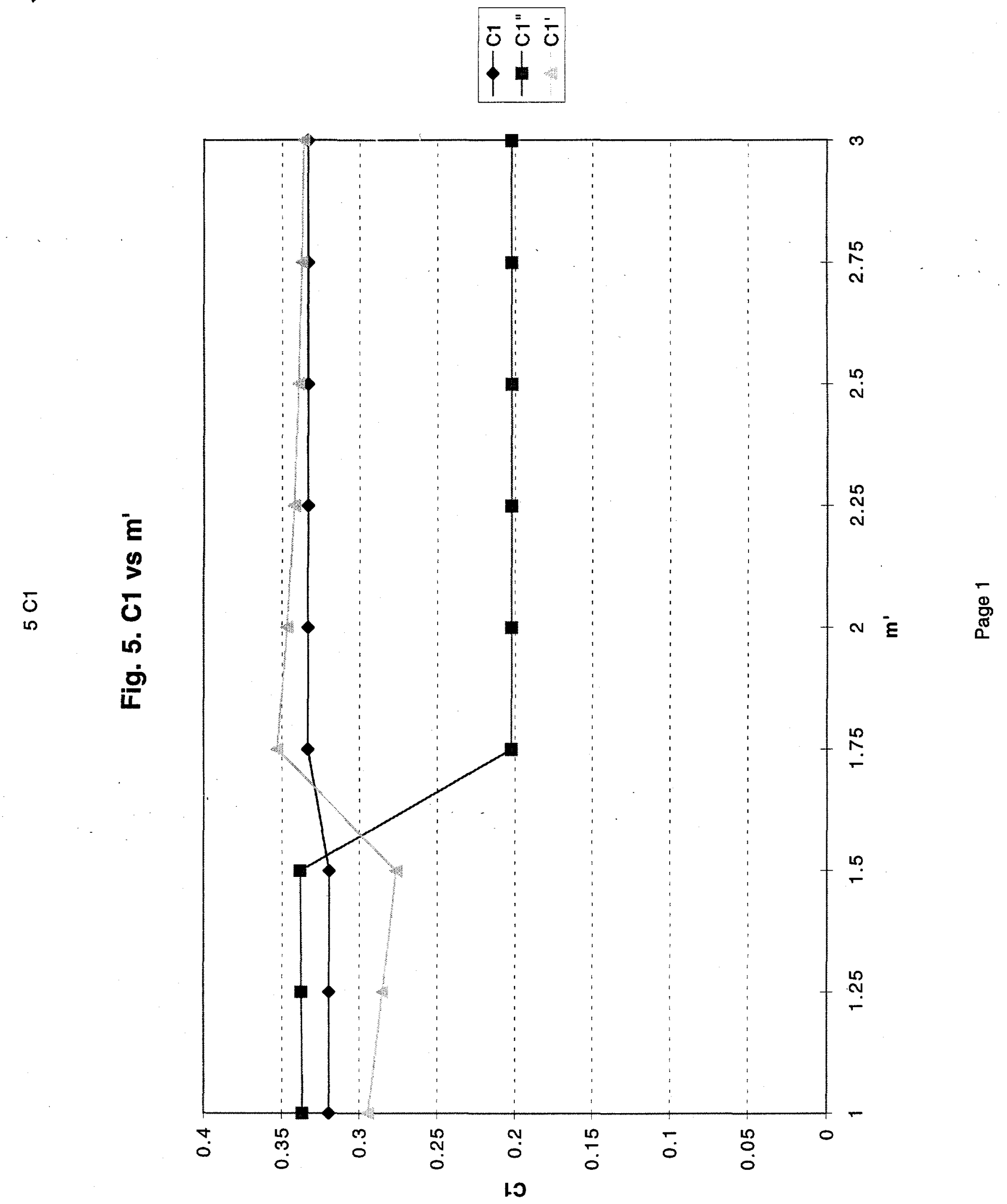


Fig. 6. C2 vs $\mathrm{m}$

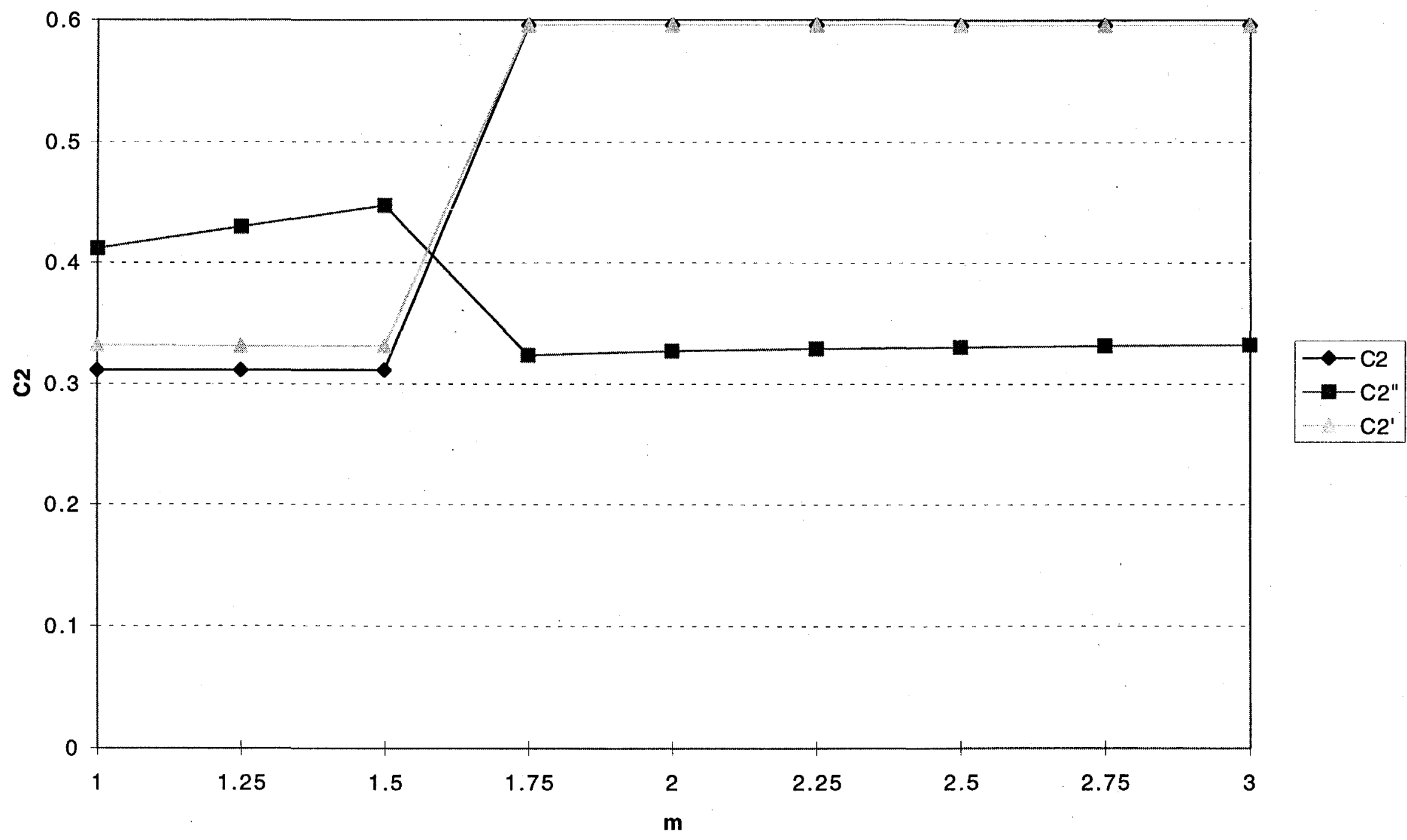

Page 1 
Fig. 7. I vs $\mathrm{m}^{\prime}$

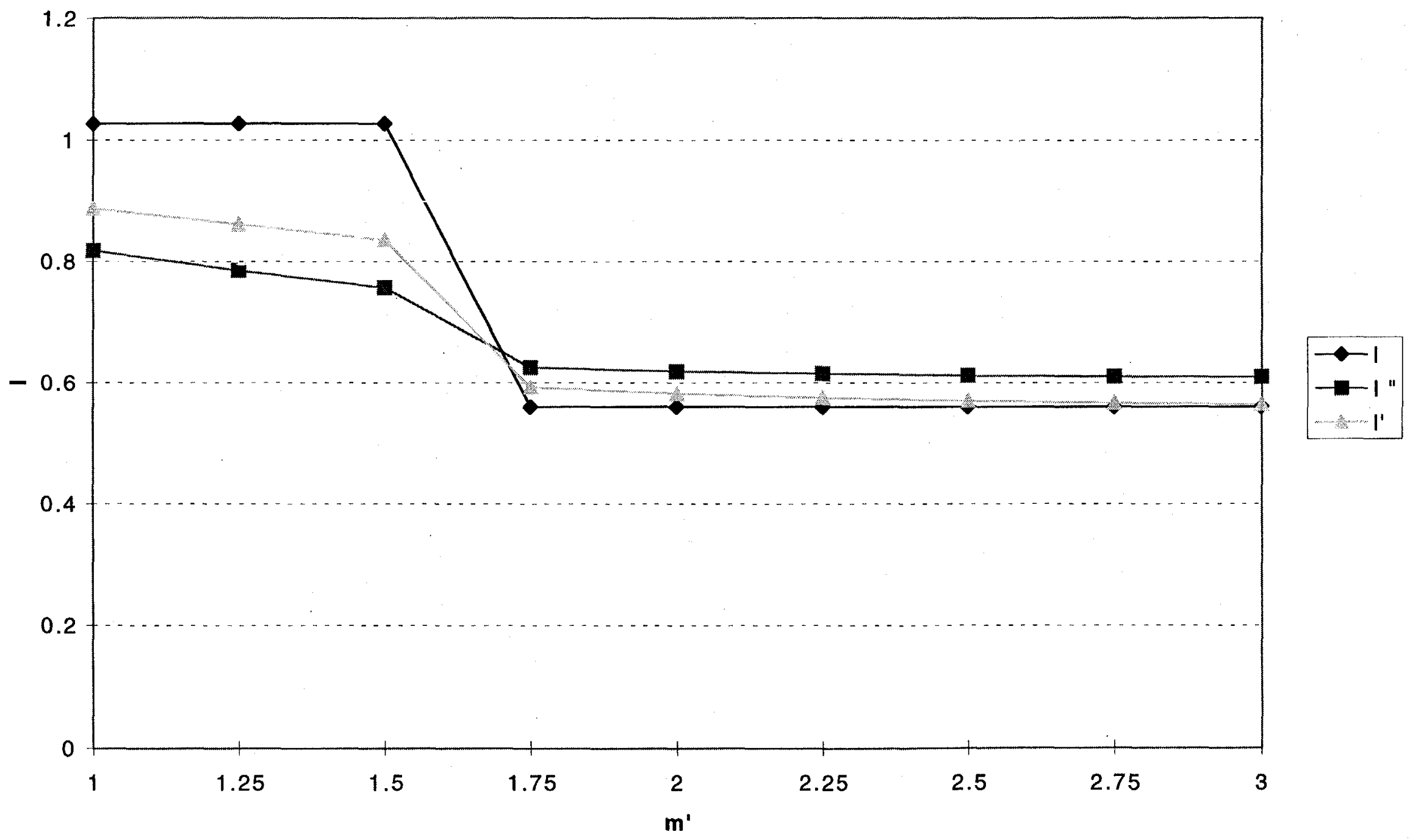

